\title{
Effect of pasteurization on the residues of tetracyclines in milk
}

\author{
Eva Kellnerová, Pavlína Navrátilová, Ivana Borkovcová \\ University of Veterinary and Pharmaceutical Sciences Brno, Faculty of Veterinary Hygiene and Ecology, \\ Department of Milk Hygiene and Technology, Brno, Czech Republic
}

Received July 31, 2014

Accepted February 25, 2015

\begin{abstract}
The main aim of this work was to determine the effect of high pasteurization of milk $\left(85^{\circ} \mathrm{C} / 3 \mathrm{~s}\right)$ on the residues of tetracycline and oxytetracycline. The samples of raw cow's milk, purchased from a vending machine, were spiked with standard solutions of tetracycline and oxytetracycline. The content of the residues of tetracycline antibiotics was measured before and after heating. Precleaned samples were extracted by a mixed-mode solid phase extraction technique and analysed using high performance liquid chromatography/diode array detection. Whereas the residues of tetracycline decreased only by $5.74 \%$ and were not significantly different $(P>0.05)$, the residues of oxytetracycline decreased by $15.3 \%$ and this distinction was highly significant $(P \leq 0.01)$. Based on the results of our study, the tetracycline antibiotics were proved to have differences in the thermostability of particular substances at pasteurisation temperatures.
\end{abstract}

Antibiotics, heat treatment, thermostability

Tetracyclines are a group of highly important broad-spectrum antibiotics used in veterinary medicine to treat food-producing animals (Botsoglou and Fletouris 2001; W ang et al. 2012). They are used to treat gastrointestinal, respiratory, genitourinary and skin bacterial infections as well as infectious diseases of the musculoskeletal system and systemic infections, and also in the treatment of cholera and sepsis (Samanidou et al. 2007). However, they have a range of side effects, including disturbances in healthy intestinal microflora, allergic reactions, liver and kidney malfunctions, hypersensitiveness and intense-light related dermatitis. Moreover, nowadays it is necessary to take into account the relatively high probability of acquired tetracycline resistance (Michalova et al. 2004).

In order to protect consumers' health, EU legislation lays down the maximum residue limit (MRL) in food of animal origin for veterinary medical products approved for use in foodproducing animals. Legislation establishes the MRL for three tetracycline antibiotics most commonly used in lactating dairy cows. The MRL for tetracycline (TTC), oxytetracycline (OTC) and chlortetracycline (CTC) in cow's milk is $100 \mu \mathrm{g} \cdot \mathrm{kg}^{-1}$ (Commission Regulation $37 / 2010$ ). When heated or exposed to acidic or highly alkaline environments, tetracyclines are subject to chemical transformation processes, such as isomerization and epimerization (Wang et al. 2012). For this reason, when establishing MRLs it is necessary to take into account both the basic compound (tetracycline) and its epimers (the 4-epimer products of TTC, OTC and CTC) (Commission Regulation 37/2010; Spisso et al. 2010).

Information concerning thermal stability of drug residues in food is toxicologically important. Most food of animal origin is not eaten raw, but requires heat treatment: boiling or poaching, frying, roasting or stewing. These culinary processes may lead to protein denaturation, increase in temperature, water and fat loss and changes in $\mathrm{pH}$, which in turn may result in changes in the residues' concentration, chemical structure and chemical reactions as well as to their loss of solubility. Many drugs are chemically unstable to

Address for correspondence:

MVDr. Navrátilová Pavlína, Ph.D

Department of Milk Hygiene and Technology

Faculty of Veterinary Hygiene and Ecology

University of Veterinary and Pharmaceutical Sciences Brno

Palackého tř. $1 / 3,61242$ Brno

Phone +420 541562716

E-mail: navratilovap@ vfu.cz

http://www.vfu.cz/acta-vet/actavet.htm 
some extent and thus prone to degradation during storage and thermal or technological processing (Botsoglou and Fletouris 2001).

One of the basic methods of thermal processing of raw milk is pasteurization. Compared to other food of animal origin, milk is subjected to only a very short heat treatment. The results of many studies show that pasteurization does not lead to full inactivation and degradation of drug residues (Botsoglou and Fletouris 2001).

Even members of the same class of antibiotics with the same structure may exhibit vast differences in thermal stability, depending on different matrix types and conditions of the treatment. When heated, tetracyclines split and degrade into metabolites, which indicate lack of thermal stability among this group of drugs. The degree of instability may vary with temperature. Many other questions are still to be answered. Thermal processing may not only reduce the concentration of drug residues in food, but it can also change their pharmacological and toxic effects (Hsieh et al. 2011). Heat treatment may give rise to new chemical compounds with higher levels of toxicity than that of the parent compound (Botsoglou and Fletouris 2001).

The presence of veterinary drug residues in milk is important from the hygienic point of view as an important quality marker, and also from the technological point of view. Presence of drug residues poses a risk especially for dairy product manufacture, for it may interfere with dairy cultures.

The main objective of this study was to determine the effect of the most basic heat treatment used in dairy industry - pasteurization - on the residues of tetracycline (TTC) and oxytetracycline (OTC) in milk.

\section{Materials and Methods}

Milk samples

Raw cow's milk was obtained from a vending machine during July and August 2013. All milk samples came from the Agros Vyškov-Dědice, a.s. farm.

\section{Sample preparation}

A preliminary heating of the sample to $40{ }^{\circ} \mathrm{C}$ was carried out prior to pasteurization. Then the sample was cooled to ca $20^{\circ} \mathrm{C}$ and subjected to a centrifugation process at $2,490 \times \mathrm{g}$ for $10 \mathrm{~min}$ in order to remove fatty constituents. Subsequently, an antibiotic solution was added to create milk samples with concentrations close to $1.5 \times \operatorname{MRL}\left(c=150 \mu \mathrm{g} \cdot \mathrm{l}^{-1}\right)$. The concentration of tetracyclines in the samples was measured before and after heat treatment (high pasteurization at $85^{\circ} \mathrm{C}$ for $3 \mathrm{~s}$ ).

Pre-analytical processing of the milk samples consisted in precipitation of protein components, which was done by mixing the samples with McIlvaine buffer with ethylenediaminetetraacetic acid (EDTA) and centrifugation at $2490 \times \mathrm{g}$ for $5 \mathrm{~min}$. The supernatant obtained was adjusted to $\mathrm{pH} 10$ by sodium hydroxide $(\mathrm{NaOH})$ solution $\left(c=1 \mathrm{~mol} \cdot \mathrm{l}^{-1}\right)$. Sample purification was done using a solid phase extraction (SPE) vacuum system and MixedMode Oasis MAX columns (3 cc, $60 \mathrm{mg}$, Waters, USA). Subsequently, the sample was eluted by a 45:55 mixture of acetonitrile and oxalic acid $\left(c=7.5 \times 10^{-2} \mathrm{~mol} \cdot \mathrm{l}^{-1}\right)$. Before analysis the solution was diluted with distilled water to the volume of $1.5 \mathrm{ml}$.

\section{Chromatographic conditions}

Measurements were carried out using a high performance liquid chromatograph (HPLC) Alliance 2695 with photo diode array detector (PDA) 2996 (Waters, USA). Separation was performed on a Nova-Pak C8 column, $4 \mu \mathrm{m}, 3.9 \times 150 \mathrm{~mm}$, UV detection at $355 \mathrm{~nm}$. Non-linear gradient elution was used. Mobile phase A consisted of oxalic acid $\left(c=1.2 \times 10^{-2} \mathrm{~mol} \cdot 1^{-1}\right)$ and mobile phase $\mathrm{B}$ consisted of a mixture of acetonitrile and methanol (1:1) with a flow rate of $0.8 \mathrm{ml} / \mathrm{min}$. Column temperature was $35^{\circ} \mathrm{C}$, sample injection $30 \mu 1$.

\section{Validation indicators of HPLC method}

Method calibration was carried out by means of matrix samples analysis. Standards of OTC, TTC, and CTC were added to the samples of raw cow's milk to create concentrations ranging from 0.02 to $1.0 \mathrm{mg} \cdot \mathrm{l}^{-1}$, and they were analysed using a standard procedure. The linearity of determination was established from the values of the calibration curve and was verified on the basis of the values of the correlation coefficient R (CTC R $=0.994$, TTC $\mathrm{R}=0.997$, OTC R $=0.988$ ). Recovery and repeatability of the OTC, TTC, and CTC determination was established by means of parallel analysis of the milk samples with the addition of standards of known concentration at levels of 0.5 and $0.1 \mathrm{mg} \cdot \mathrm{l}^{-1}$ for each analyte (Table 1 ). 
Table 1. High performance liquid chromatography method parameters.

\begin{tabular}{lccc}
\hline Parameter & Oxytetracycline & Tetracycline & Chlortetracycline \\
\hline Recovery (\%) & 93.30 & 91.50 & 88.10 \\
RSD (\%) & 5.10 & 11.70 & 9.90 \\
n & 12 & 12 & 12 \\
Repeatability & & & 11.70 \\
RSD (\%) & 9.26 & 12.18 & 15 \\
n & 15 & 15 & \\
\hline
\end{tabular}

$\mathrm{RSD}=$ relative standard deviation, $\mathrm{n}=$ number of measurements

\section{Statistical evaluation}

The obtained results were processed and evaluated using a paired $t$-test in STAT Plus (Unistat software ver. 5.1; Unistat Ltd. 1998). This program was also used to establish the basic statistical parameters. Differences were considered significant at $P \leq 0.05$, highly significant at $P \leq 0.01$.

\section{Results}

The effect of heat treatment (high pasteurization at $85{ }^{\circ} \mathrm{C}$ for $3 \mathrm{~s}$ ) on OTC and TTC residues in milk is shown in Table 2 . Table 2 also reports the results of statistical analysis of measured values. The acquired results confirm the differences in thermostability between the tetracycline analytes. The mean concentration of TTC was $169 \pm 15.84 \mu \mathrm{g} \cdot l^{-1}$ in raw milk and $159.84 \pm 9.23 \mu \mathrm{g} \cdot \mathrm{l}^{-1}$ in pasteurized milk. The pasteurization caused a mean decrease in TTC residues by $5.74 \%$. Paired $t$-test evaluation of both groups (non-heated and heated milk) did not reveal any significant differences $(P>0.05)$. In the case of OTC samples, however, the differences in mean values of raw and pasteurized milk were found to be highly significantly different $(P \leq 0.01)$; pasteurization decreased the OTC concentration by $15.3 \%$. The mean concentration of OTC in milk samples dropped from $163.28 \pm 13.94 \mu \mathrm{g} \cdot \mathrm{l}^{-1}$ to $138.29 \pm 11.35 \mu \mathrm{g} \cdot 1^{-1}$ during heat treatment. These results indicated that TTC was more stable than OTC. Results suggested that heating under pasteurization conditions could cause only a partial reduction of OTC and TTC residues.

Table 2. Statistical evaluation of oxytetracycline and tetracycline residues content in raw and pasteurized milk $\left(85^{\circ} \mathrm{C} / 3 \mathrm{~s}\right)$.

\begin{tabular}{|c|c|c|c|c|}
\hline & \multicolumn{2}{|c|}{ Oxytetracycline $\left[\mu \mathrm{g} \cdot 1^{-1}\right]$} & \multicolumn{2}{|c|}{ Tetracycline $\left[\mu \cdot \mathrm{gl}^{-1}\right]$} \\
\hline & Raw milk & $\begin{array}{l}\text { Pasteurized } \\
\text { milk }\end{array}$ & Raw milk & $\begin{array}{l}\text { Pasteurized } \\
\text { milk }\end{array}$ \\
\hline $\mathrm{n}$ & 12 & 12 & 12 & 12 \\
\hline $\bar{x}$ & 163.28 & 138.29 & 169.58 & 159.84 \\
\hline SD & 13.94 & 11.35 & 15.84 & 9.23 \\
\hline Min & 135.90 & 116.10 & 148.30 & 143.30 \\
\hline $\operatorname{Max}$ & 177.10 & 152.00 & 201.60 & 180.00 \\
\hline Paired $t$-test & \multicolumn{2}{|c|}{$\begin{array}{l}\text { Highly significant difference } \\
\qquad(p=0.01)\end{array}$} & \multicolumn{2}{|c|}{$\begin{array}{l}\text { Non-significant differences } \\
(p>0.05)\end{array}$} \\
\hline
\end{tabular}

$\bar{x}$ - arithmetic mean, $\mathrm{n}$ - number of measurements, SD - standard deviation, Min - minimum concentration, Max - maximum concentration 


\section{Discussion}

Most foods of animal origin are not eaten raw, but require heat treatment before consumption. Heat treatment involving varying combinations of time and temperature depending on the intended use of the starting product - while at the same time ensuring health quality - is an essential part of industrial treatment of raw milk. Along with ultra heat treatment (UHT) and sterilization, pasteurization is one of the basic and most common heat treatment methods. In accordance with current legislation, pasteurization involves either short time heat treatment at very high temperatures (at least $72{ }^{\circ} \mathrm{C}$ for $15 \mathrm{~s}$ ) or long time treatment at low temperatures (at least $63{ }^{\circ} \mathrm{C}$ for $30 \mathrm{~min}$ ) and/or the use of any other combination of time and temperature that has an equivalent effect. Pasteurized milk must show a negative reaction to alkaline phosphatase test (Commission Regulation 1662/2006).

The effect of heat treatment on residues of antimicrobial substances has been studied by a number of researchers (Botsoglou and Fletouris 2001; Hassani et al. 2008; Loksuwan 2002; Hsieh et al. 2011). However, these studies often use matrices other than milk (e.g. meat, aqueous solution, buffer solution) and they also use different temperatures and different methods of thermostability evaluation. Very few studies have dealt with the effects of pasteurization on the concentration of tetracycline residues in milk.

Examples include Loksuwan (2002), who studied the effects of low-temperature long-time (LTLT) pasteurization $\left(63{ }^{\circ} \mathrm{C} / 30 \mathrm{~min}\right)$ on OTC, CTC, and TTC residues in raw milk. The OTC residues were in samples with concentration of $100 \mu \mathrm{g} \cdot \mathrm{l}^{-1}$ inactivated to such an extent that they could not be detected; at concentrations of $200 \mu \mathrm{g} \cdot \mathrm{l}^{-1}$ and $300 \mu \mathrm{g} \cdot \mathrm{l}^{-1}$ the starting OTC concentrations were found to have dropped by $86.7 \%$ and $79.36 \%$, respectively. In case of TTC residues, the decrease was distinctively smaller: it amounted to $54.75 \%$ in samples with TTC concentration of $100 \mu \mathrm{g} \cdot \mathrm{l}^{-1}$ and to $22.97 \%$ and $37.45 \%$ in concentrations of $200 \mu \mathrm{g}^{-1} \mathrm{l}^{-1}$ and $300 \mu \mathrm{g} \cdot \mathrm{l}^{-1}$, respectively. In contrast, degradation of CTC was very limited: the drug residue concentration decreased by only $9.57 \%\left(100 \mu \mathrm{g} \cdot \mathrm{l}^{-1}\right), 4.88 \%\left(200 \mu \mathrm{g} \cdot \mathrm{l}^{-1}\right)$, and $3.71 \%\left(300 \mu \mathrm{g} \cdot \mathrm{l}^{-1}\right)$.

The temperature and time used in our study were different than in the study of Loksuw an (2002). If we compare the decrease in TTC and OTC concentrations in the two studies, it is clear that the heat treatment we chose $\left(85^{\circ} \mathrm{C} / 3 \mathrm{~s}\right)$ was less effective in eliminating tetracycline residues. The temperature we used $\left(85^{\circ} \mathrm{C}\right)$ was higher; however, it appears that the degradation of residues is affected by the heating time as well, which explains the significant difference in the values obtained in the two studies. Both studies show that OTC in milk is more labile when subjected to heat treatment than TTC. Overall, our data confirm the published results which show that pasteurization temperatures lead to the decrease in OTC and TTC residues in milk, but they do not cause complete degradation of the substances.

Pasteurization is not the only technological procedure employed in the dairy industry. Other ways of thermal processing of milk include ultra heat treatment (UHT) and sterilisation, which aim to devitalise the vegetative bacterial forms and spores in raw milk, including enzyme inactivation, in order to extend the shelf life of milk. Both UHT and sterilisation use temperatures above $100{ }^{\circ} \mathrm{C}$. Ultra heat treatment requires temperatures of at least $135{ }^{\circ} \mathrm{C}$ for a period of up at least 1 second (usually $3-5 \mathrm{~s}$ ), which is followed by aseptic filling (Deeth and Datta 2003; Commission Regulation 1662/2006). Sterilization, on the other hand, involves continuous sterilization with aseptic filling and hermetic sealing in final containers, using an effective heat treatment duration; higher temperatures are combined with shorter times (Hinrichs and Atamer 2003).

Hsieh et al. (2011) studied the effects of the above heat treatment on tetracycline thermostability, using double-distilled water as a matrix. They used two different heating temperatures $\left(100^{\circ} \mathrm{C}, 121^{\circ} \mathrm{C}\right)$ with the same time of exposure $(15 \mathrm{~min})$. Their findings show that higher temperatures $\left(121^{\circ} \mathrm{C} / 15 \mathrm{~min}\right)$ cause tetracycline degradation of up 
to $99 \%$. At $100{ }^{\circ} \mathrm{C}$ the degradation was less extensive, amounting to as little as $54.4 \%$. The results of this study clearly show that the degree of TTC and CTC degradation is temperature-dependent. In OTC samples, however, both temperatures led to the same degree of degradation. In addition to these findings, tetracyclines have been found to have different degradation profiles at $100{ }^{\circ} \mathrm{C}$. The results of this study demonstrate, similarly as ours, that even members of the same group of tetracyclines with the same structure may exhibit vast differences in thermostability. For this reason, the thermostability of drugs cannot be predicted from their membership in a particular group of medicaments.

Hassani et al. (2008) set out to determine the thermostability of OTC and TTC in McIlvaine buffer with varying $\mathrm{pH}$ value $(\mathrm{pH} 7.0,5.5$ and 4.0) and in the same McIlvaine buffer of $\mathrm{pH} 7$ containing sodium chloride $(\mathrm{NaCl})$ at high and ultra high temperatures ranging from $110-140^{\circ} \mathrm{C}$. The results of the study showed that sterilization $\left(118^{\circ} \mathrm{C} / 30 \mathrm{~min}\right.$ and $121^{\circ} \mathrm{C} / 20 \mathrm{~min}$ ) reduced the concentration of TTC and OTC to very small, negligible amounts (less than $0.01 \%$ ). The UHT, on the other hand, reduced OTC concentrations by more than $40 \%$ and TTC concentrations by roughly $30 \%$. At $135{ }^{\circ} \mathrm{C} / 15 \mathrm{~s}$ the UHT inactivated OTC residues by $44 \%$ and TTC residues by $24 \%$. It follows that while the sterilization process degraded tetracyclines in milk by more than $98 \%$, UHT milk still retained about 50 to $90 \%$ of the initial concentrations of tetracyclines. Differences in $\mathrm{pH}$ levels and water activity $\left(\mathrm{a}_{\mathrm{w}}\right)$ had little effect on tetracycline thermostability.

Comparing the results of some of the studies with our own is difficult due to differences in matrix, result verification methods and applied thermal conditions. The degradation and inactivation of antibiotic residues during heat treatment can be influenced by a number of factors: matrix, temperature, chemical structure of the antibiotic and its stability (the formation of active and inactive metabolites from the original substance). Other factors can also impact the results, e.g. the binding capacity of antibiotics to other milk components and the used methods of antibiotic residue measurement (biological or physicochemical methods). The basic method of heat treatment of milk used in the dairy industry pasteurization - does not ensure a complete degradation of tetracycline antibiotics. From the technological point of view, the decreasing of TTC and OTC in milk during hightemperature pasteurization $\left(85^{\circ} \mathrm{C}\right.$ for $3 \mathrm{~s}$ ) determined in this study is not significant.

Our study confirms that the thermostability of individual drugs varies significantly within the group of tetracycline antibiotics. Compared to TTC, OTC displays lower thermostability during high-temperature pasteurization $\left(85^{\circ} \mathrm{C} / 3 \mathrm{~s}\right)$. The content of OTC residues dropped by $15.3 \%$ when subjected to this type of heat treatment. The content of TTC residues, on the other hand, dropped by only $5.7 \%$.

\section{Acknowledgements}

This work was created with the financial support of NAZV “KUS” QJ1230044 project.

\section{References}

Botsoglou NA, Fletouris DJ 2001: Drug Residues in Foods: Pharmacology, food safety, and analysis. Marcel Dekker, New York, 1194 p.

Commission Regulation (EC) No 1662/2006 of 6 November 2006 amending Regulation (EC) No 853/2004 of the European Parliament and of the Council laying down specific hygiene rules for food of animal origin. OJ L 320: $1-10$

Commission Regulation (EU) No 37/2010 of 22 December 2009 on pharmacologically active substances and their classification regarding maximum residue limits in foodstuffs of animal origin. OJ L 15: 1-77

Deeth HC, Datta N 2003: Ultra-high temperature treatment (UHT): Heating systems. In: Roginski H (Ed.): Encyclopedia of Dairy Sciences. Academic Press, Amsterdam, pp. 2642-2652

Hassani M, Lázaro R, Pérez C, Condón S, Pagán R 2008: Thermostability of oxytetracycline, tetracycline, and doxycycline at ultrahigh temperatures. J Agr Food Chem 56: 2676-2680

Hinrichs J, Atamer Z 2003: Sterilization of milk and other products. In: Roginski H (Ed.): Encyclopedia of Dairy Sciences. Academic Press, Amsterdam, pp. 2569-2576 
Hsieh MK, Shyu CL, Liao JW, Franje CA, Huang YJ, Chang SK, Shih PY, Chou CC 2011: Correlation analysis of heat stability of veterinary antibiotics by structural degradation, changes in antimicrobial activity and genotoxicity. Vet Med-Czech 56: 274-285

Loksuwan J 2002: The effect of heating on multiple residues of tetracyclines in milk. Thammasat Int J Sc Tech 7: 17-21

Michalova E, Novotna P, Schlegelova J 2004: Tetracyclines in veterinary medicine and bacterial resistance to them. Vet Med-Czech 49: 79-100

Samanidou VF, Nikolaidou KI, Papadoyannis IN 2007: Advances in chromatographic analysis of tetracyclines in foodstuffs of animal origin-a review. Sep Purif Rev 36: 1-69

Spisso BF, Monteiro MA, Pereira MU, Ferreira RG, Da Costa RP, Cruz TA, Da Nóbrega AW 2010: Pilot survey of commercial pasteurized milk consumed in the metropolitan area of Rio de Janeiro, Brazil, for tetracyclines residues, including the 4 -epimers of oxytetracycline, tetracycline and chlortetracycline. Food Addit Contam B 3: $220-227$

Wang J, Mac Neil JD, Kay JF 2012: Chemical Analysis of Antibiotic Residues in Food. John Wiley \& Sons, New Jersey, $384 \mathrm{p}$. 